\title{
Testosterone in Relation to Behavioral Problems in Pre-Pubertal Boys With Autism Spectrum Disorders
}

\author{
A. PIVOVARCIOVA ${ }^{1}$, J. DURDIAKOVA ${ }^{\mathbf{1}}$, S. HNILICOVA ${ }^{\mathbf{1}}$, D. FILCIKOVA ${ }^{\mathbf{1}}$, \\ D. OSTATNIKOVA ${ }^{1}$
}

${ }^{1}$ Institute of Physiology, Academic Research Center for Autism, Faculty of Medicine, Comenius University, Bratislava, Slovakia

Received March 27, 2015

Accepted June 30, 2015

On-line December 15, 2015

\section{Summary}

Autism spectrum disorders (ASD) are neurodevelopmental conditions characterized by impairment in social communication and presence of stereotyped/restricted behaviors. Children with ASD very often demonstrate co-morbid psychiatric problems, problems known to be affected by testosterone in neurotypical populations. However, there are few reports investigating relationships between testosterone and psychiatric conditions in children with ASD. The aim of this study was to determine the relationship between plasmatic levels of testosterone and behavioral/emotional problems in pre-pubertal boys with ASD. The study sample consisted of 31 pre-pubertal boys (ages 3-10) with ASD. Parents completed the Nisonger Child Behavior Rating Form (NCBRF) to assess specific behavioral/emotional problems as observed in the previous 2 months. Plasmatic testosterone levels were determined in boys according to standardized procedures. It was found that there were positive correlations between testosterone levels and the conduct problems subscale $(p=0.034, r s=0.382)$ of NCBRF and also between testosterone levels and the hyperactive subscale $(p=0.025, r s=0.402)$ of NCBRF. Findings in this study are in line with research conducted in the neurotypical population. This is the first large study investigating testosterone and emotional/behavioral problems in ASD and warrants further research in this field in order to clarify the etiopathogenesis of psychiatric co-morbidities and improve their treatment.

\section{Key words}

Autism spectrum disorders • Testosterone • Conduct problems • Hyperactivity

\section{Corresponding author}

A. Pivovarciova, Institute of Physiology, Academic Research Center for Autism, Faculty of Medicine, Comenius University, Sasinkova 2, 81372 Bratislava, Slovakia. Fax: +421-2-59357515. E-mail: anna.pivovarciova@gmail.com

\section{Introduction}

Autism spectrum disorders (ASD) are a set of heterogeneous neurodevelopmental conditions, characterized by early-onset difficulties in social communication and unusually restricted, repetitive behavior and interests. The worldwide prevalence is about 1\% (Babinska et al. 2014, Lai et al. 2014). Children with ASD have often comorbid emotional and behavioral symptoms including irritability and aggression, hyperactivity, anxiety and depression (Gadow et al. 2005, 2012, Hallett et al. 2013, Simonoff et al. 2008, Vickerstaff et al. 2007). Previous studies suggested that as many as three-fourths of individuals with ASD might reach the diagnostic threshold for a bona fide coexisting psychiatric disorder (Brereton et al. 2006), including attention-deficit/hyperactivity disorder (ADHD), anxiety disorders, affective disorders and oppositional defiant disorder (de Bruin et al. 2007, Green et al. 2000, Simonoff et al. 2008). These disorders may exacerbate functional impairment and core ASD features. Children with ASD very often have a unique clinical presentation of psychiatric conditions, usually accompanied by atypical symptoms (Magnuson and Constantino 2011, Simonoff et al. 2008), compared to 
neurotypical children, and it was also observed that their psychopharmacological responses may be atypical as well (Handen et al. 2000).

Sex differences in human behavior, personality and tendency to emotional states are well documented, and research on sex differences has found that boys/men tend to have problems that are more externalized (e.g. aggression, dominance-seeking behavior) and are less prone to internalize problems (e.g. depression, anxiety or low self-esteem) than girls/women (Feingold 1994, Kessler et al. 1993, Klein et al. 2015). It is assumed that testosterone may play a role in the etiology of aggression (Barzman et al. 2013, Carre et al. 2011, Golubchik et al. 2009) and mood-related variables such as depression or self-esteem (McHenry et al. 2014, Parizek et al. 2014, Vermeersch et al. 2013). These studies are conducted in neurotypical children/adults of both genders and, to our knowledge, there are just two reports employing small samples that investigated relationships between testosterone and psychiatric conditions in children with ASD (Pivovarciova et al. 2014, Tordjman et al. 1997). Moreover, neurodevelopmental disorders such ADHD and ASD occur more often in boys than girls (Davies 2014, Lai et al. 2014). Thus, investigating the etiological role of testosterone in psychiatric conditions affecting children with ASD might better clarify their specific etiopathogenesis and the need for further treatment.

The purpose of this paper is to determine the relationship between plasmatic levels of testosterone and behavioral and emotional problems in pre-pubertal boys with ASD. We hypothesized that predominantly "male" behavioral problems such as conduct disorder symptoms and ADHD symptoms might positively correlate with actual levels of plasmatic testosterone in pre-pubertal boys with ASD.

\section{Methods}

Design of the study and selection of subjects

The study was approved by the Ethical Committee of the Faculty of Medicine, Comenius University (FM CU), Bratislava, Slovakia and it has been performed in accordance with the Declaration of Helsinki (2000) of the World Medical Association. ASD children in our study were recruited after diagnostic procedures (in the Academic Research Center for Autism, Institute of Physiology, FM CU) and after confirming the diagnosis of ASD (see description of diagnostic procedures below). After one parent signs the consent form, 31 pre-pubertal boys with ASD between 3 and 10 years of age were enrolled in our study. Parents then completed the Nisonger Child Behavior Rating Form (NCBRF) and venous blood was drawn from children according to standardized procedures (see biochemical procedure below).

In order to avoid gender differences only boys were enrolled in the study. We also decided to enroll only pre-pubertal subjects ( $\leq 10$ years old) in order to avoid large variability in sex hormone levels described in children of pubertal age (Sperling 2008).

\section{Diagnosis of ASD and measurement of behavioral/ emotional problems}

The diagnosis of ASD was determined by a clinical psychologist or psychiatrist according to ICD 10 and children also underwent behavioral testing by trained specialists at the Academic Research Center for Autism, Institute of Physiology, FM CU. The diagnostic tools involved: observation of a child by the Autism Diagnostic Observation Schedule - second revision (ADOS-2) and the Autism Diagnostic Interview Revised (ADI-R), a comprehensive interview administered to parents that provides a thorough assessment of individuals with ASD (Lord et al. 2000, 1994). All children enrolled to the study had to meet the criteria for ASD on both autism scales. Parents of the children with ASD completed the Nisonger Child Behavior Rating Form (NCBRF) version for parents (Aman et al. 1996). NCBRF is a behavior rating scale with good psychometric properties designed for children and adolescents with intellectual disabilities (Aman et al. 1996). This scale also has good psychometric properties and also has been widely used in clinical and research practice in populations of children and adolescents with ASD (Lecavalier et al. 2004). The behavior of subjects was assessed in two major areas: social competence and problem behavior. The 10 social competence items are distributed on two subscales: Compliant/Calm (e.g. accepted redirection, followed rules, initiated positive interactions) and Adaptive/Social (e.g. participated in group activities, shared with others, stayed on task). Items are rated on a four-point Likert scale ranging from not true (0) to completely or always true (3). The 66 problem behavior items are also rated on a four-point Likert scale. Raters are instructed to consider both the rate of occurrence and the degree to which the behavior was a problem over the last month. Ratings can vary from "did not occur" or "was not a problem" (0) to "occurred 
a lot" or "was a serious problem" (3). There are 66 items that are distributed on six subscales: (1) Conduct Problem (e.g. explosive, easily angered, gets in physical fights, argues, violates rules, tantrums), (2) Insecure/ Anxious (e.g. nervous/tense, overly anxious to please others, easily embarrassed, silent and moody), (3) Hyperactive (e.g., difficulty concentrating, easily distracted, fidgets/wiggles, overactive), (4) Self-Injury/Stereotypic (e.g., hits or slaps own head or other body parts, rocks body back and forth repetitively, self-scratching, self-biting), (5) SelfIsolated/Ritualistic (e.g., apathetic or unmotivated, has rituals, shy around others, isolates self from others), and (6) Overly Sensitive (e.g., crying, tearful episodes, easily frustrated, feelings easily hurt).

\section{Biochemical procedure}

Venous blood samples were drawn into sterile polypropylene tubes containing K2 EDTA (Sarstedt, Nümbrecht, Germany) using standardized procedures the same month of a year from 8:00 to 10:00 a.m. from all children at the Pediatric Department of Children Faculty Hospital CU in Bratislava. Whole blood samples were centrifuged for $5 \mathrm{~min}$ at $2000 \mathrm{~g}$ immediately after collection. Plasma aliquots were stored at $-20{ }^{\circ} \mathrm{C}$ for not longer than one month. On the day of testing, frozen samples were brought to room temperature and pipetted on to a testing plate. The ELISA assay using a commercial Testosterone ELISA kit and an Estradiol ELISA kit were used according to manufacturer's instructions (DRG Instruments $\mathrm{GmbH}$, Marburg, Germany). The intra-assay coefficient of variation was $3.3 \%$ and the inter-assay coefficient of variation was $6.2 \%$.

\section{Statistical analysis}

Statistical analyses were done using Graph Pad Prism 5 (Graph Pad software, San Diego, USA). Correlations between hormonal levels and behavioral scores were assessed using the Spearman correlation test due to the non-parametric distribution of the sample.

\section{Results}

The aim of this study was the determination of the relationship between plasmatic levels of testosterone and behavior subscales of NCBRF in pre-pubertal boys with ASD. Positive correlation between total plasmatic testosterone levels and conduct problem subscale of NCBRF ( $p=0.034, r s=0.382)$ was observed and a positive correlation between total testosterone and hyperactive subscale of NCBRF ( $p=0.025, r s=0.402)$ was found. No other correlations with other social competence and problem behavior subscales of NCBRF and testosterone levels were found (see correlation matrix in Table 1 and Figure $1 \mathrm{a}, \mathrm{b}$ ).

\section{Discussion}

Many children with ASD demonstrate co-morbid psychiatric problems, problems known to be affected by steroid hormones according to research done in a neurotypical population. Although there are lines of research supporting idea about testosterone involvement in the etiopathogenesis of ASD, studies about the relationship between testosterone and psychiatric co-morbidities in the ASD population are few (Pivovarciova et al. 2014, Tordjman et al. 1997). Our study is the first large study investigating correlations between plasmatic testosterone levels and behavioral problems in prepubertal boys with ASD.

In our study it was found that there was positive correlation between total plasmatic testosterone levels and the conduct problem subscale of NCBRF. Conduct disorders and aggressive behavior have been related to increased prenatal and postnatal testosterone levels, in the neurotypical population of children (Barzman et al. 2013, Golubchik et al. 2009) and adults (Bailey and Hurd 2005, Carre et al. 2011, Dabbs et al. 1987, Montoya et al. 2012). Aggression is generally more often present in boys than in girls in the neurotypical population (Lansford et al. 2006) although gender has consistently not been associated with aggression in children with ASD (Kanne and Mazurek 2011, Murphy et al. 2009). To our knowledge, there are two brief reports discussing the question of whether higher testosterone levels are related to aggressive symptoms in children with ASD, comparing them with neurotypical children and ASD children without aggression. Tordjman et al. (1997) measured plasma testosterone in nine patients with ASD compared to a group of neurotypical children. The nine adolescent children with ASD were divided into three groups comprised of (1) those aggressive against others, (2) those who are self-mutilating, and (3) a group that had the withdrawal characteristic of ASD. The group that exhibited aggression against others had higher testosterone levels than any of the comparison subjects. However, the other autistic patients showed normal adrenal androgen levels. Similarly, in our recent initial 
Table 1. Correlation matrix table (including correlation coefficients $r s$ ) with the variables analyzed in groups of boys with ASD, $p$-values less than 0.05 were considered significant.

\begin{tabular}{|c|c|c|c|c|c|c|c|}
\hline $\begin{array}{l}\text { Compliant/ } \\
\text { calm }\end{array}$ & $\begin{array}{l}\text { Adaptive } \\
\text { social }\end{array}$ & $\begin{array}{l}\text { Conduct } \\
\text { problems }\end{array}$ & $\begin{array}{l}\text { Insecure/ } \\
\text { Anxious }\end{array}$ & $\begin{array}{l}\text { Hyper- } \\
\text { active }\end{array}$ & $\begin{array}{l}\text { Self- } \\
\text { injury/ } \\
\text { stereotypic }\end{array}$ & $\begin{array}{l}\text { Self- } \\
\text { isolated/ } \\
\text { ritualistic }\end{array}$ & $\begin{array}{l}\text { Overly } \\
\text { sensitive }\end{array}$ \\
\hline $\begin{array}{l}-0.303 \\
(\mathrm{p}=0.098)\end{array}$ & $\begin{array}{l}-0.082 \\
(\mathrm{p}=0.661)\end{array}$ & $\begin{array}{l}0.383 \\
(p=0.034)\end{array}$ & $\begin{array}{l}0.194 \\
(\mathrm{p}=0.295)\end{array}$ & $\begin{array}{l}0.402 \\
(\mathrm{p}=0.025)\end{array}$ & $\begin{array}{l}0.180 \\
(\mathrm{p}=0.333)\end{array}$ & $\begin{array}{l}0.061 \\
(p=0.746)\end{array}$ & $\begin{array}{l}0.343 \\
(p=0.059)\end{array}$ \\
\hline
\end{tabular}

A)

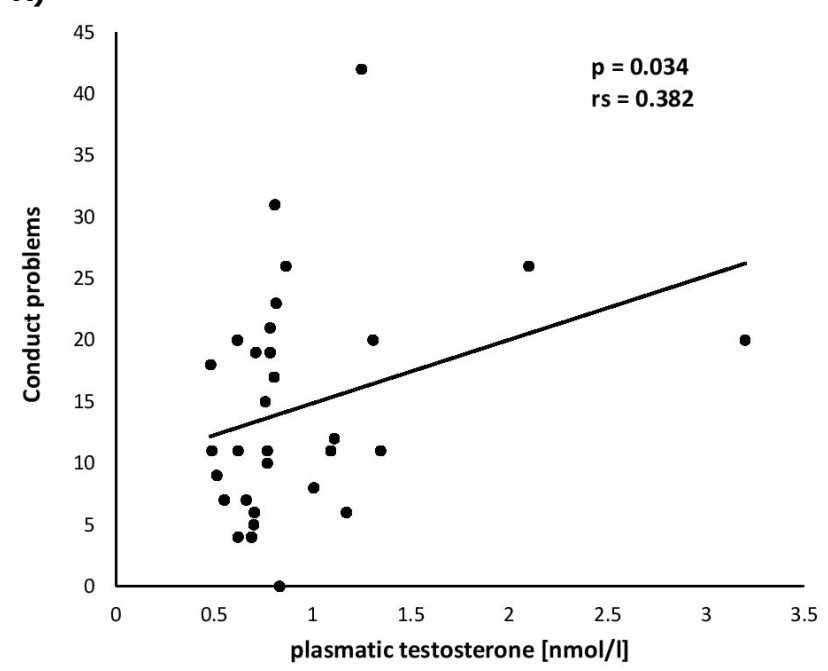

B)

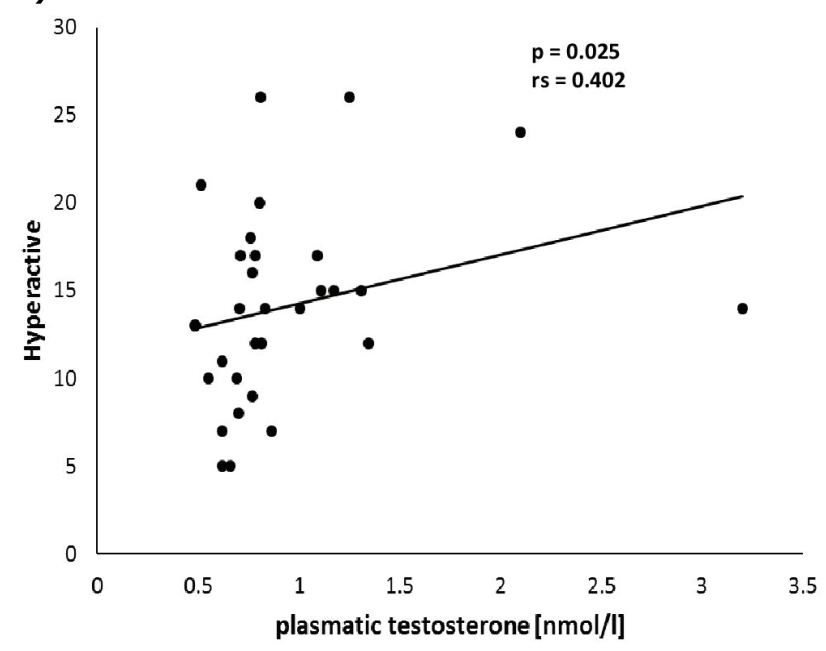

Fig. 1. Correlation graphs (including correlation coefficients $r s$ ) with the variables analyzed in pre-pubertal boys with ASD, $p$-values less than 0.05 were considered significant. There are total testosterone levels on axes $\mathrm{x}$ and scores in problem behavior subscales of NCBRF (conduct problems, hyperactive) on axes y. A): Positive correlation between total plasmatic testosterone levels and total scores on conduct problem subscale $(p=0.034, r s=0.382)$ of NCBRF, B): positive correlation between total plasmatic testosterone and total scores on hyperactive subscale of NCBRF $(p=0.025, r s=0.402)$ report (Pivovarciova et al. 2014), only one of the three pre-pubertal boys with ASD who engaged in a specific type of aggression had an abnormally high level of plasmatic testosterone compared to a group of neurotypical control children; the rest of the ASD patients had no significant difference in testosterone levels compared to the control group. In both of these studies higher testosterone levels and aggressive behavior in children with ASD were observed comparing to neurotypical children or other children with ASD.

Attention deficit hyperactivity disorder (ADHD) is a neurodevelopmental disorder that is characterized by a combination of severe inattention, extreme impulsiveness across the variety of domains, and hyperactivity (Tonhajzerova et al. 2014). In a neurotypical population, the lines of evidence support the idea that elevated androgen levels (especially prenatally) may confer increased vulnerability to ADHD (Davies 2014). ADHD is generally more often present in boys than in girls in a neurotypical population although gender has consistently not been associated with ADHD in children with ASD (Brereton et al. 2006, Simonoff et al. 2008). In our study, testosterone levels were found to be positively correlated with the hyperactive subscale of NCBRF. According to NCBRF, hyperactive subscale items (e.g. difficulty concentrating, easily distracted, fails to finish things he/she starts) are symptoms often related to ADHD. To our knowledge, there are no studies investigating a relationship between actual testosterone levels and ADHD symptoms in ASD children. However, there are studies conducted in children with ASD that show a positive relationship between prenatal levels of testosterone and ADHD symptoms in these children (de Bruin et al. 2006, Romero-Martinez et al. 2013). Moreover, it was reported that high intrauterine testosterone levels may be partially involved in the development of both disorders: ADHD and ASD that may point to common pathways in etiopathogenesis of 
both disorders (Davies 2014, Romero-Martinez et al. 2013).

Our results need to be interpreted with regard to the limitations of the current study. This is a pilot study with a minimal number of subjects. In the future, relationships between testosterone and behavioral/ emotional problems should be studied in females with ASD as well as with other age categories in order to generalize our findings (Freitag 2014). Another limitation pertains to the instrument used. Although there were significant advantages over other methods, a standardized behavior rating scale of present symptoms is limited by the range of items included. For example, there is large under-recognition of co-morbidities (e.g. anxiety and depressive symptomatology) in ASD children due to atypical symptoms and lack of specific assessment tools for co-morbidities in these individuals (Magnuson and Constantino 2011), which can contribute to the aforementioned limitation. Along the same lines, the results were dependent on the accuracy of information obtained from informants (parents). In future research, assessment of particular problem behavior in real time based on experimental design during functional behavioral analysis might be useful in order to obtain more detailed qualitative and quantitative characteristics such as function, frequency, intensity, and duration of aggressive episodes (Iwata et al. 1994, Mace et al. 1986). In future research it is necessary to study relationships between testosterone and co-morbidities in a more comprehensive way, taking into consideration complex androgen activity (Durdiakova et al. 2011) and not only total plasmatic testosterone levels (e.g. sensitivity of androgen receptor, activity of enzymes involved in testosterone metabolism). Moreover, it is very unlikely that testosterone solely plays a role in the etiology of co-morbidities and the potential relationship between testosterone and other hormones (cortisol, oxytocine, estradiol) might be taken into consideration.

\section{Conclusions}

Despite the limitations to the findings, the results have important implications. Psychiatric conditions are very frequent and unique in children/adults with ASD. These disorders may exacerbate functional impairment and core ASD features and may have a serious impact on children with ASD as well as their families and society. Considerable evidence exists that testosterone plays a role in the etiopathogenesis of psychiatric conditions in neurotypical populations. However, there is insufficient information about this relationship in children with ASD. Our study is the first bigger study investigating the potential relationship between testosterone and emotional/behavioral problems in ASD and warrants further research in this field in order to clarify the etiopathogenesis of psychiatric co-morbidities and improve consequent treatment and prevention (Klasen et al. 2015).

\section{Conflict of Interest}

There is no conflict of interest.

\section{Acknowledgements}

This study emerged as a part of the Autism research project held at the Academic Research Center for Autism (ARCA) at the Institute of Physiology, Faculty of Medicine, Comenius University, Bratislava, Slovakia, supported by grants: University Science Park for Biomedicine Bratislava (ITMS 26240220087) and APVV 0254-11.

\section{References}

AMAN MG, TASSE MJ, ROJAHN J, HAMMER D: The Nisonger CBRF: a child behavior rating form for children with developmental disabilities. Res Dev Disabil 17: 41-57, 1996.

BABINSKA K, BUCOVA M, DURMANOVA V, LAKATOSOVA S, JANOSIKOVA D, BAKOS J, HLAVATA A, OSTATNIKOVA D: Increased plasma levels of the high mobility group box 1 protein (HMGB1) are associated with a higher score of gastrointestinal dysfunction in individuals with autism. Physiol Res 63 (Suppl 4): S613-S618, 2014.

BAILEY AA, HURD PL: Finger length ratio (2D:4D) correlates with physical aggression in men but not in women. Biol Psychol 68: 215-222, 2005.

BARZMAN DH, MOSSMAN D, APPEL K, BLOM TJ, STRAWN JR, EKHATOR NN, PATEL B, DELBELLO MP, SORTER M, KLEIN D, GERACIOTI TD Jr: The association between salivary hormone levels and children's inpatient aggression: a pilot study. Psychiatr Q 84: 475-484, 2013. 
BRERETON AV, TONGE BJ, EINFELD SL: Psychopathology in children and adolescents with autism compared to young people with intellectual disability. J Autism Dev Disord 36: 863-870, 2006.

CARRE JM, MCCORMICK CM, HARIRI AR: The social neuroendocrinology of human aggression. Psychoneuroendocrinology 36: 935-944, 2011.

DABBS JM Jr, FRADY RL, CARR TS, BESCH NF: Saliva testosterone and criminal violence in young adult prison inmates. Psychosom Med 49: 174-182, 1987.

DAVIES W: Sex differences in attention Deficit Hyperactivity Disorder: candidate genetic and endocrine mechanisms. Front Neuroendocrinol 35: 331-346, 2014.

DE BRUIN EI, VERHEIJ F, WIEGMAN T, FERDINAND RF: Differences in finger length ratio between males with autism, pervasive developmental disorder-not otherwise specified, ADHD, and anxiety disorders. Dev Med Child Neurol 48: 962-965, 2006.

DE BRUIN EI, FERDINAND RF, MEESTER S, DE NIJS PF, VERHEIJ F: High rates of psychiatric co-morbidity in PDD-NOS. J Autism Dev Disord 37: 877-886, 2007.

DURDIAKOVA J, OSTATNIKOVA D, CELEC P: Testosterone and its metabolites - modulators of brain functions. Acta Neurobiol Exp (Wars) 71: 434-454, 2011.

FEINGOLD A: Gender differences in personality: a meta-analysis. Psychol Bull 116: 429-456, 1994.

FREITAG C: Neurobiology and treatment of adolescent female conduct disorder: FemNAT-CD consortium: a new European cooperation. Eur Child Adolesc Psychiatry 23: 723-724, 2014.

GADOW KD, DEVINCENT CJ, POMEROY J, AZIZIAN A: Comparison of DSM-IV symptoms in elementary schoolage children with PDD versus clinic and community samples. Autism 9: 392-415, 2005.

GADOW KD, GUTTMANN-STEINMETZ S, RIEFFE C, DEVINCENT CJ: Depression symptoms in boys with autism spectrum disorder and comparison samples. J Autism Dev Disord 42: 1353-1363, 2012.

GOLUBCHIK P, MOZES T, MAAYAN R, WEIZMAN A: Neurosteroid blood levels in delinquent adolescent boys with conduct disorder. Eur Neuropsychopharmacol 19: 49-52, 2009.

GREEN J, GILCHRIST A, BURTON D, COX A: Social and psychiatric functioning in adolescents with Asperger syndrome compared with conduct disorder. J Autism Dev Disord 30: 279-293, 2000.

HALLETT V, LECAVALIER L, SUKHODOLSKY DG, CIPRIANO N, AMAN MG, MCCRACKEN JT, MCDOUGLE CJ, TIERNEY E, KING BH, HOLLANDER E, SIKICH L, BREGMAN J, ANAGNOSTOU E, DONNELLY C, KATSOVICH L, DUKES K, VITIELLO B, GADOW K, SCAHILL L: Exploring the manifestations of anxiety in children with autism spectrum disorders. J Autism Dev Disord 43: 2341-2352, 2013.

HANDEN BL, JOHNSON CR, LUBETSKY M: Efficacy of methylphenidate among children with autism and symptoms of attention-deficit hyperactivity disorder. J Autism Dev Disord 30: 245-255, 2000.

IWATA BA, DORSEY MF, SLIFER KJ, BAUMAN KE, RICHMAN GS: Toward a functional analysis of self-injury. J Appl Behav Anal 27: 197-209, 1994.

KANNE SM, MAZUREK MO: Aggression in children and adolescents with ASD: prevalence and risk factors. J Autism Dev Disord 41: 926-937, 2011.

KESSLER RC, MCGONAGLE KA, SWARTZ M, BLAZER DG, NELSON CB: Sex and depression in the National Comorbidity Survey. I: Lifetime prevalence, chronicity and recurrence. J Affect Disord 29: 85-96, 1993.

KLASEN F, OTTO C, KRISTON L, PATALAY P, SCHLACK R, RAVENS-SIEBERER U; BELLA STUDY GROUP: Risk and protective factors for the development of depressive symptoms in children and adolescents: results of the longitudinal BELLA study. Eur Child Adolesc Psychiatry 24: 695-703, 2015.

KLEIN AM, OTTO Y, FUCHS S, REIBIGER I, VON KLITZING K: A prospective study of behavioral and emotional symptoms in preschoolers. Eur Child Adolesc Psychiatry 24: 291-299, 2015.

LAI MC, LOMBARDO MV, BARON-COHEN S: Autism. Lancet 383: 896-910, 2014.

LANSFORD JE, MALONE PS, STEVENS KI, DODGE KA, BATES JE, PETTIT GS: Developmental trajectories of externalizing and internalizing behaviors: factors underlying resilience in physically abused children. Dev Psychopathol 18: 35-55, 2006.

LECAVALIER L, AMAN MG, HAMMER D, STOICA W, MATHEWS GL: Factor analysis of the Nisonger Child Behavior Rating Form in children with autism spectrum disorders. J Autism Dev Disord 34: 709-721, 2004. 
LORD C, RUTTER M, LE COUTEUR A: Autism Diagnostic Interview-Revised: a revised version of a diagnostic interview for caregivers of individuals with possible pervasive developmental disorders. J Autism Dev Disord 24: 659-685, 1994.

LORD C, RISI S, LAMBRECHT L, COOK EH Jr, LEVENTHAL BL, DILAVORE PC, PICKLES A, RUTTER M: The autism diagnostic observation schedule-generic: a standard measure of social and communication deficits associated with the spectrum of autism. J Autism Dev Disord 30: 205-223, 2000.

MACE FC, PAGE TJ, IVANCIC MT, O'BRIEN S: Analysis of environmental determinants of aggression and disruption in mentally retarded children. Appl Res Ment Retard 7: 203-221, 1986.

MAGNUSON KM, CONSTANTINO JN: Characterization of depression in children with autism spectrum disorders. J Dev Behav Pediatr 32: 332-340, 2011.

MCHENRY J, CARRIER N, HULL E, KABBAJ M: Sex differences in anxiety and depression: role of testosterone. Front Neuroendocrinol 35: 42-57, 2014.

MONTOYA ER, TERBURG D, BOS PA, VAN HONK J: Testosterone, cortisol, and serotonin as key regulators of social aggression: a review and theoretical perspective. Motiv Emot 36: 65-73, 2012.

MURPHY O, HEALY O, LEADER G: Risk factors for challenging behaviors among 157 children with autism spectrum disorder in Ireland. Res Autism Spectr Disord 3: 474-482, 2009.

PARIZEK A, MIKESOVA M, JIRAK R, HILL M, KOUCKY M, PASKOVA A, VELIKOVA M, ADAMCOVA K, SRAMKOVA M, JANDIKOVA H, DUSKOVA M, STARKA L: Steroid hormones in the development of postpartum depression. Physiol Res 63 (Suppl 2): S277-S282, 2014.

PIVOVARCIOVA A, HNILICOVA S, TOMOVA A, OSTATNIKOVA D, MACE FC: Testosterone and explosive aggression in children with autism spectrum disorders. Eur Neuropsychopharmacol 24 (Suppl 2): S712-S713, 2014.

ROMERO-MARTINEZ A, POLDERMAN TJ, GONZALEZ-BONO E, MOYA-ALBIOL L: Masculinization in parents of offspring with autism spectrum disorders could be involved in comorbid ADHD symptoms. J Atten Disord 2013 , in press.

SIMONOFF E, PICKLES A, CHARMAN T, CHANDLER S, LOUCAS T, BAIRD G: Psychiatric disorders in children with autism spectrum disorders: prevalence, comorbidity, and associated factors in a population-derived sample. J Am Acad Child Adolesc Psychiatry 47: 921-929, 2008.

SPERLING MA: Pediatric Endocrinology, Third Ed. SPERLING MA (ed), Elsevier Health Sciences, Philadelphia, 2008.

TONHAJZEROVA I, ONDREJKA I, FARSKY I, VISNOVCOVA Z, MESTANIK M, JAVORKA M, JURKO A Jr, CALKOVSKA A: Attention deficit/hyperactivity disorder (ADHD) is associated with altered heart rate asymmetry. Physiol Res 63 (Suppl 4): S509-S519, 2014.

TORDJMAN S, FERRARI P, SULMONT V, DUYME M, ROUBERTOUX P: Androgenic activity in autism. $A m J$ Psychiatry 154: 1626-1627, 1997.

VERMEERSCH H, T'SJOEN G, KAUFMAN JM, VAN HOUTTE M: ESR1 polymorphisms, daily hassles, anger expression, and depressive symptoms in adolescent boys and girls. Horm Behav 63: 447-453, 2013.

VICKERSTAFF S, HERIOT S, WONG M, LOPES A, DOSSETOR D: Intellectual ability, self-perceived social competence, and depressive symptomatology in children with high-functioning autistic spectrum disorders. J Autism Dev Disord 37: 1647-1664, 2007. 